\title{
Neural Crest Stem Cell-specific Deletion of the Pygopus2 Gene Modulates Hair Follicle Development
}

\author{
Alla Narytnyk • Kevin Gillinder • Bernard Verdon • \\ Oliver Clewes • Maya Sieber-Blum
}

Published online: 18 August 2013

(C) The Author(s) 2013. This article is published with open access at Springerlink.com

\begin{abstract}
We show that neural crest stem cells affect mouse hair follicle development. During embryogenesis hair follicle induction is regulated by complex reciprocal and functionally redundant signals between epidermis and dermis, which remain to be fully understood. Canonical Wnt signalling is a hallmark of neural crest cells and also a prerequisite for hair follicle induction prior to hair placode formation in the epidermis. As neural crest stem cells invade the epidermis during early embryonic development we aimed at determining whether neural crest cells affect hair follicle development. To attenuate, but not silence, canonical Wnt signalling specifically in neural crest cells, we analyzed Wnt1-cre(+/-)::Pygo2(-/-) mice in which the $\beta$-catenin co-activator gene, Pygopus 2 (Pygo2), is deleted specifically in neural crest cells. Both, hair density and hair thickness were reduced in mutant mice. Furthermore, hair development was delayed and the relative ratio of hair types was affected. There was a decrease in zig-zag hairs and an increase in awl hairs. Mouse neural crest stem cells expressed ectodysplasin, an essential effector in the formation of zig-zag hair. Taken together, our data support the novel notion that neural crest cells are involved in the earliest stages of hair follicle development.
\end{abstract}

Keywords Neural crest · Hair follicle · Pygopus 2 - Wnt · Zig-zag hair $\cdot$ Awl hair

\section{Introduction}

This study addresses aspects of hair follicle formation. Prior to morphological changes in the ectoderm, the first phase of hair induction (hair stage 0 and earlier) is regulated by epidermal

A. Narytnyk $\cdot$ K. Gillinder $\cdot$ B. Verdon $\cdot$ O. Clewes $\cdot$ M. Sieber-Blum $(\bowtie)$

Institute of Genetic Medicine, Newcastle University, Centre for Life, Central Parkway, Newcastle upon Tyne NE1 3BZ, UK

e-mail: maya.sieber-blum@ncl.ac.uk
Wnt signalling, which is an absolute requirement for hair induction $[1,46]$. In the absence of activated $\beta$-catenin, epidermal stem cells fail to differentiate into follicular keratinocytes, but instead adopt an epidermal fate [18]. Epidermal Wnt proteins expressed early in development are essential for subsequent uniform dermal Wnt signalling [3]. The stage of placode formation (hair stage 1) is primarily characterized by Eda-A1 (ectodysplasin) signalling through its cognate receptor Edar, which is expressed in epidermal cells and upon activation leads to downstream NFKB and Wnt10a/b signalling [38].

Neural crest stem cells transiently express Wnt1 during early emigration from the neural tube. The only other cells that express Wnt1 during embryonic development are dorsal neural tube cells of the future spinal cord [5]. Wnt1-driven Cre recombinase permanently excises loxP-flanked genes of interest. In order to delete Pygo2 early in development and specifically in neural crest stem cells, we therefore crossed Wnt1-cre mice with transgenic mice that have a loxP-flanked Pypogus2 (Pygo2) gene.

Pygo2 is one of the genes that comprise the neural crest stem cell molecular signature [17] but was not detected in epidermal stem cells [33]. Functionally, Pygo 2 is an enhancer of $\beta$-catenin function in canonical Wnt signalling [19, 23]. In the developing skin, Pygo 2 is expressed in scattered cells within the onelayered undifferentiated epidermis before it is expressed in hair placodes and then more widely in the epidermis [22].

In addition to Pygo2, embryonic neural crest cells express Wnt proteins [8], the Wnt receptors, Frizzled (Fzd) and LRP [43, 46, 47, 49], and they actively signal through the canonical Wnt pathway [5, 6, 44]. A subset of multipotent neural crest stem cells migrate laterally from the neural tube below the ectoderm, invade the ectoderm [34] and eventually settle in the bulge of hair follicles [4, 17, 40, 41]. As global Pygo2 knockout mice have a reduced hair density [23] these observations raised the question whether neural crest cells are involved in hair follicle formation at the pre-placode stage. 


\section{Materials and Methods}

Animals and Genotyping

Work with mice was approved by the Newcastle University review board under license numbers 60/3621 and 60/3876. The following transgenic mouse lines were used: Wnt1-cre (gift of A McMahon; [5]), Rosa26-LacZ (R26R; gift of P Soriano; [42]) and Pygo2 (gift of S Potter; [39]). Wnt1-cre $(+/-)$ mice were crossed with Pygo2(+/-) mice to obtain Wnt1-cre(+/-)::Pygo2(-/-) double transgenic mice ("Wnt1cre (+/-)::Pygo(-/-)") in which Pygo2 is deleted exclusively in neural crest cells as well as Wnt1-cre(+/-)::Pygo $(+/+)$ control littermates. For visualizing neural crest cells in mutant mice, Wnt1-cre(+/-)::Pygo2(+/-) mice were bred and then crossed with R26R(+/-)::Pygo(+/-) mice in order to obtain Wnt1-cre(+/-)::R26R(+/-)::Pygo2(-/-) triple transgenic mice in which Pygo 2 is deleted in a neural crest-specific way and neural crest cells can be visualized by their expression of $\beta$-glactosidase. Control littermates were Wnt1cre $(+/-):: R 26 \mathrm{R}(+/-)::$ Pygo2(+/+). Double and triple transgenic animals were born with the expected Mendelian ratio, were indistinguishable from normal littermates and fed normally. Most mutant mice, however, died within the first 24 $48 \mathrm{~h}$ postnatally. The cause of death might be connected to a significant decrease of neural crest cells in the enteric nervous system (unpublished data). This deficiency could lead to Hirschsprung disease-like problems, which are lethal. Therefore, $\mathrm{P} 0$ back skin from neonates was studied. For genotyping, tail biopsies were boiled in $25 \mathrm{mM} \mathrm{NaOH} / 0.2 \mathrm{mM}$ EDTA (Sigma-Aldrich) for $20 \mathrm{~min}$ and then re-buffered with an equal volume of $40 \mathrm{mM}$ Tris-Cl (Sigma-Aldrich). Up to $5 \mu \mathrm{l}$ of buffered extract was used per PCR reaction. For detection of Wnt1-cre and R26R, the primers and PCR conditions used were exactly as described previously [45]. For detection of the Pygo2(flox/-) allele the following primers (Integrated DNA Technologies) Wnt1-cre(+/-)::Pygo(-/-) allele, forward (F) CCTGGATTCTTGTTGCTGGTATG; reverse (R) AAGGTATTTGGTGCTCCGAGGG; Pygo2 WT or floxed allele, (F) TGTCTTGATGACAGCGTTTAGCC, (R) AGAT TCAGTAAGCTGAGCCTGGTG [39]. PCR conditions were as follows: 1 cycle, $94{ }^{\circ} \mathrm{C}$ for $3 \mathrm{~min}$, followed by 35 cycles consisting of $30 \mathrm{~s}$ denaturation at $94{ }^{\circ} \mathrm{C}, 30 \mathrm{~s}$ annealing at $62{ }^{\circ} \mathrm{C}$, and $45 \mathrm{~s}$ extension at $72{ }^{\circ} \mathrm{C}$ and a final $10 \mathrm{~min}$ extension at $72{ }^{\circ} \mathrm{C}$. PCR products were resolved on $1.5 \%$ agarose gels.

\section{Neural Crest Cultures}

E9.5 mouse embryos were obtained from timed pregnant C57BL/6J females (The Jackson Laboratory). Neural tubes were dissected and cultured exactly as we have described [18]. Briefly, dissected trunk tissue was treated with trypsin and then triturated to remove somites and the notochord.
Subsequently, neural tubes were placed into Cell-Start coated culture plates. Large numbers of neural crest cells emigrated overnight from the neural tubes and the cultures were fixed $18 \mathrm{~h}$ post-explantation.

Immunohistochemistry

Neural crest cultures were fixed with $4 \%$ paraformaldehyde (Sigma) for $30 \mathrm{~min}$, rinsed, and incubated overnight in the cold with FITC-conjugated Ectodermal Dysplasia 1 antibody at 1:100 (orb15540; biorbyt, Cambridge). The next day the cultures were rinsed exhaustively and mounted with Vectashield plus DAPI (H1200; Vector Laboratories) and a coverslip.

\section{Paraffin Tissue Processing}

Tissue used for haematoxylin/eosin (H\&E) staining, and Xgal staining was processed as follows. After dissection in PBS, fixation with $4 \%$ PFA at $4{ }^{\circ} \mathrm{C}$ overnight following by PBS rinse, tissue was trimmed and dehydrated in a $70 \%, 95 \%$, $100 \% \times 2$ ethanol series for $1 \mathrm{~h}$ each. They were then incubated $2 \times 20 \mathrm{~min}$ in xylene, followed by a $50 \%, 75 \%, 100 \%$ exchange with liquid paraffin for 20 min each in paraffin wells. Tissue was incubated in liquid paraffin overnight at $60^{\circ} \mathrm{C}$. The next day liquid paraffin was exchanged, the tissue embedded, paraffin blocks trimmed, mounted, and $7 \mu \mathrm{m} \mathrm{sec-}$ tions prepared. Sections were collected on SuperFrost Plus microscope slides (Menzel-Gläser; VWR) and dried overnight at $42{ }^{\circ} \mathrm{C}$.

\section{Haematoxylin and Eosin Staining}

For H\&E staining slides were first deparaffined in xylene $(2 \times 5 \mathrm{~min})$ and rehydrated through ethanol series $(100 \% \times 2$, $90 \%, 70 \%, 50 \%$, and $30 \%$ ) for 5 min each at RT. After a 5 min water rinse they were stained in haematoxylin (Thermo Scientific) for $20 \mathrm{~s}$, rinsed with water, blued in Scott's tap water (Sigma-Aldrich; $10 \mathrm{~s}$ ), rinsed, stained with eosin (Thermo Scientific) for $20 \mathrm{~s}$, rinsed, dehydrated $(50 \%, 70 \%, 100 \%$ ethanol for $1 \mathrm{~min}$ each) and processed through an equal xylene series (3 min each). Slides were mounted with DPX mounting medium (VWR), coverslipped, dried, and observed under bright field optics.

\section{Morphometrical Analysis}

Hair follicle density analysis was performed as described previously [30]. Cross-sections of the back skin of 3 mutant and 3 wild type mice were taken at and parallel to the skin surface and H\&E stained. Images were captured and using Adobe Photoshop, $1 \times 10^{4} \mu \mathrm{m}$ square grids were applied to the images. Hair follicles were counted within gridded field areas to calculate the number of hair follicles per $1 \times 10^{4} \mu \mathrm{m}^{2}$. In 
total, 260 areas $\left(260 \times 1 \times 10^{4} \mu \mathrm{m}^{2}\right)$ from mutant skin and 252 areas from wild type control littermates were scored and statistically analysed.

To determine the cross sectional area of hair follicles, images were processed with AxioVision software (Carl Zeiss Microscopy). Overall, 676 hair follicles were measured from wild type animals and 575 hair from mutant animals from three animals of each genotype.

Morphometrical staging analysis was performed as described by Glotzer et al. [11], using criteria according to Paus et al. [31]. Longitudinal sections of back skin from 3 mutant and 3 wild type animals were prepared and H\&E stained. To avoid staging of the same follicle twice every tenth section was analysed. Three hundred two mutant and 304 wild type hair follicles were staged from three animals for each genotype.

\section{X-gal Staining}

For X-gal staining back skin was dissected in PBS (SigmaAldrich), and processed in cushioned histological cassettes to avoid skin curling. X-gal staining was performed as described previously by Pennisi et al. [30] with modifications. After $1 \mathrm{~h}$ fixation in ice cold $4 \%$ PFA at room temperature on a shaker, samples were washed $3 \times 10 \mathrm{~min}$ in wash buffer consisting of $0.01 \%$ sodium deoxycholate (Sigma-Aldrich), $0.02 \%$ NP-40 (Sigma-Aldrich), $2 \mathrm{mM} \mathrm{MgCI} 2$ in PBS) followed by incubation in X-gal staining solution consisting of $5 \mathrm{mM}$ Potassium ferricyanide (Sigma-Aldrich), $5 \mathrm{mM}$ Potassium ferrocyanide (Sigma-Aldrich), $2 \mathrm{mM} \mathrm{MgCI}_{2}, 0.01 \%$ Sodium deoxycholate , $0.02 \% \mathrm{NP}-40,20 \mathrm{mg} / \mathrm{ml} \mathrm{X-gal} \mathrm{(Sigma-Aldrich)} \mathrm{in} \mathrm{DMF}$ (Sigma-Aldrich) overnight at RT on the shaker in the dark. Then samples were washed in wash buffer $2 \times 10 \mathrm{~min}$ at RT, fixed in $4 \%$ PFA at $4{ }^{\circ} \mathrm{C}$ overnight and rinsed with PBS. For histochemical analyses samples were dehydrated through an ethanol series, cleared and infused with paraffin as described above. Embedding, mounting and sectioning were performed exactly as described above. Sections were counterstained with nuclear fast red using the protocol for H\&E staining; haematoxylin, Scott's tap water and eosin were replaced, however, by $5 \mathrm{~min}$ of staining with nuclear fast red, then dehydrated and mounted with DPX medium, coverslipped, dried, and analyzed under bright field optics. Images from every tenth section were acquired to quantify the amount of hair follicles with positive X-gal cells. Data were derived from two mice of each genotype; 256 hair follicles from 18 skin sections from Wnt1-cre(+/-)::Pygo(-/-) mice as well as 311 hair follicles were scored from 17 skin sections from wild type newborns.

\section{Hair Count}

Hair from the back skin of two Wnt1-cre(+/-)::Pygo2(-/-) rare survivors and from two Wnt1-cre $(+/-):: \operatorname{Pygo} 2(+/+)$ control littermates were plucked, scored and categorized according to criteria described by Schlake [36]. A total of 490 hair from two Wnt1-cre(+/-)::Pygo(-/-) and 459 hair from two wild type animals each were analyzed.

\section{Statistical Analysis}

Statistical significance was determined using the two-tailed unpaired Student's t-test (for hair density, hair follicle thickness, and neural crest cell positive hair follicles). For developmental staging, logistic regression analysis was performed using STATA software.

\section{Results}

We analyzed mutant back skin sections taken superficially and parallel to the skin surface and found that the average hair density was reduced by approximately $19 \%$ (Fig. 1). Furthermore, the average cross-section area of hair from Wnt1-cre(+/-)::Pygo(-/-) newborns was significantly smaller compared to control littermates (Fig. 1). These results showed that Wnt1-cre(+/-)::Pygo(-/-) newborn mice have fewer and thinner hair follicles.

Hair development during embryogenesis and perinatally can be divided into 6 stages according to morphology (see e.g., [36]). Thus, to analyze hair development in more detail, hair in newborns was staged. Hair stages analyzed ranged from stage 1 to 6 in both wild type and mutant mice. While in control mice $32 \%$ of follicles resided in stage $4,23 \%$ of follicles were in stage 4 in Wnt1-cre(+/-)::Pygo(-/-) mice (Fig. 2). Conversely, in Wnt1-cre(+/-)::Pygo(-/-) newborns $34 \%$ of follicles and $19 \%$ of control hair follicles remained in stage 3 . This observation indicated that there is a delay in hair follicle development in Wnt1-cre(+/-)::Pygo(-/-) newborn mice (Fig. 2).

Next we asked whether hair types are affected in Wnt1-cre(+/-)::Pygo(-l-) mice, and if so which ones. Wnt1cre(+/-)::Pygo(-/-) mice that did not die perinatally developed a coat. Hair from these mice and from Wnt1cre $(+/-)::$ Pygo(+/+) littermates were plucked and scored according to hair type, that is awl, auchen and zig-zag hairs. Guard hairs were disregarded, as there were too few of them to produce meaningful data and there was guard hair breakage, which produced artefacts. There was a $38.6 \%$ decrease in zig-zag hairs, a $73.3 \%$ increase in awl hairs, and a 2.5 -fold increase in auchen hairs in Wnt1-cre(+/-)::Pygo(-/-) mice compared to control littermates (Fig. 3). The morphology of zig-zag hair was altered in Wnt1-cre(+/-)::Pygo(-/-) mice. Zig-zag hair were shorter by about one third in Wnt1-cre(+/-)::Pygo(-/-) mice with only two to three bends, rather than the three to four bends observed in wild type mice [36]. These 


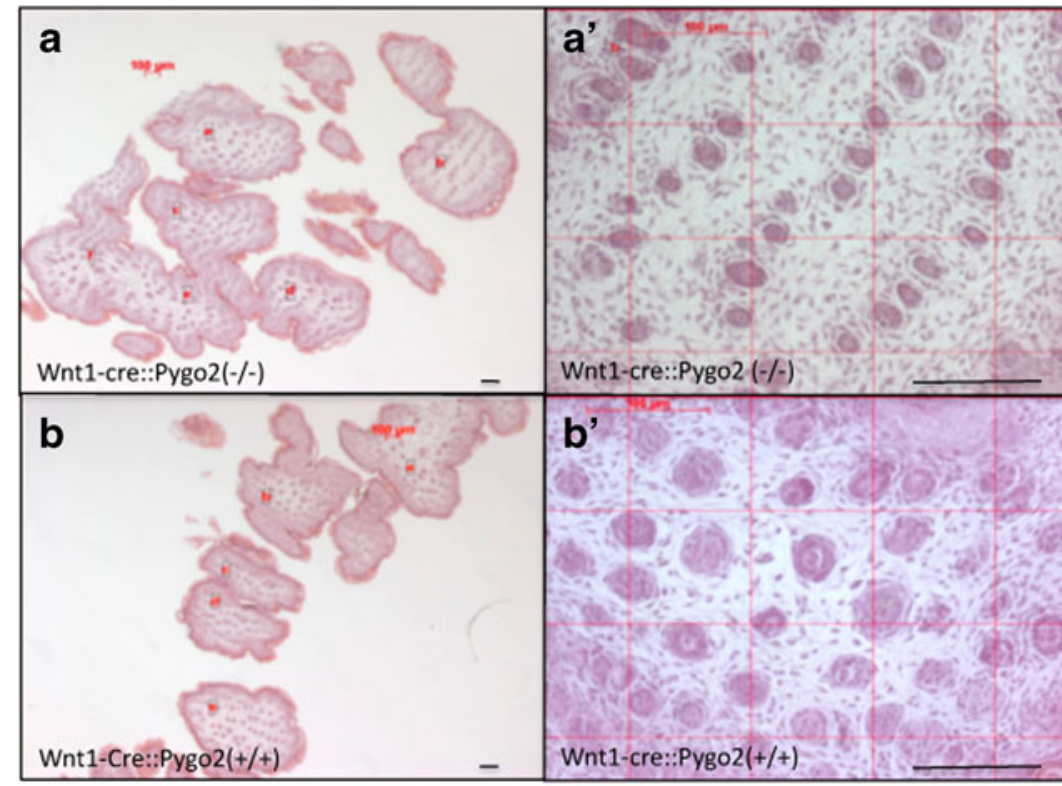

$\begin{aligned} & \text { Average hair density } \\
& \text { (number hair per } 1 \times 10^{4} \mu \mathrm{m}^{2} \text { ) }\end{aligned}$
\begin{tabular}{ll} 
Pygo2 null & $2.2 \pm 0.1$ \\
Wild type & $2.7 \pm 0.1$ \\
$p=0.003$ & \\
\hline
\end{tabular}

\section{Average area of follicle cross} section $\left(\mu \mathrm{m}^{2}\right)$

\section{Pygo2 null $429.2 \pm 7.9$ \\ Wild type $\quad 458.0 \pm 6.9$ $p=0.006$}

Fig. 1 Decreased hair thickness and hair density in Wnt1-cre(+/-)::Pygo(-/-) newborn mice. a, a' Tangential sections of back skin of Wint1cre $(+/-):$ :Pygo2(-/-) mice. Hair thickness was significantly reduced in Wnt1-cre $(+/-):$ Pygo(-/-) mice by $\sim 7 \%$. Number mice analysed, three animals per genotype. Number visual fields analysed, 31 (Wnt1cre(+/-)::Pygo(-/-), and 33 (Pygo2). Number hair measured, 575
(Wnt1-cre(+/-)::Pygo(-/-) and 676 (Pygo2). b, b' Sections from Wnt1cre $(+/-)::$ Pygo2 $(+/+)$ littermates. Average hair density was reduced by $\sim 19 \%$ in Wnt1-cre(+/-)::Pygo(-/-) mice. Number mice analysed, three animals per genotype. Number visual fields analysed, 260 (Wnt1cre(+/-)::Pygo(-/-) and 252 (Pygo2). Bars, $100 \mu \mathrm{m}$

relative proportion of these hair types as well as the morphology of zig-zag hair.
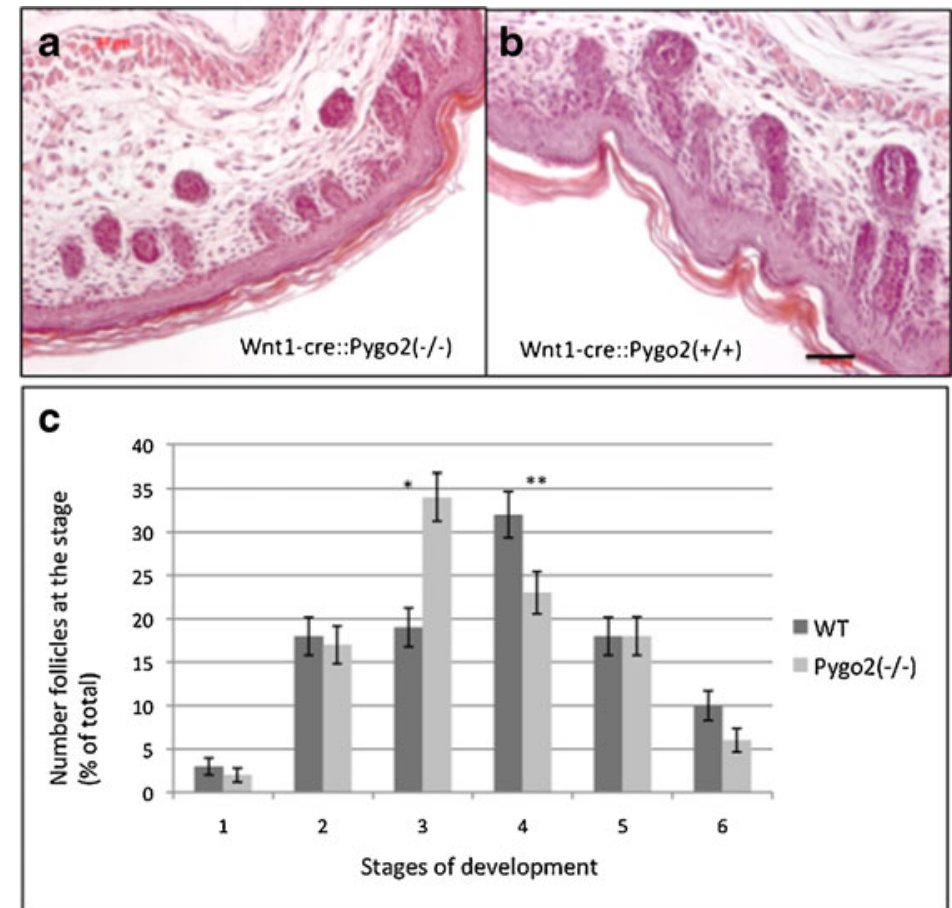

$\begin{array}{lccl}\begin{array}{l}\text { Dev. } \\ \text { Stage }\end{array} & \begin{array}{l}\text { Percent follicles at that stage } \\ \text { ( } \pm \text { S.E.M.) }\end{array} \\ & \text { Pygo2null } & \text { Wild type } & \text { p-value } \\ \text { Stage 1 } & 2 \pm 0.8 & 3 \pm 0.9 & 0.1 \\ \text { Stage 2 } & 17 \pm 2.2 & 18 \pm 2.2 & 0.6 \\ \text { Stage 3 } & 34 \pm 2.7 & 19 \pm 2.2 & <0.001 \\ \text { Stage 4 } & 23 \pm 2.4 & 32 \pm 2.7 & 0.009 \\ \text { Stage 5 } & 18 \pm 2.2 & 18 \pm 2.2 & 0.9 \\ \text { Stage 6 } & 6 \pm 1.4 & 10 \pm 1.7 & 0.06 \\ \text { Stage 7 } & 0 \pm 0.0 & 0.1 \pm 0.2 & \mathrm{n} / \mathrm{a}\end{array}$

Fig. 2 Delay in development of hair follicles in Wnt1-cre(+/-)::Pygo(-/ $-)$ newborns. Hair follicles in skin sections from Wnt1-cre $(+/-):$ :Pygo2 $(-/-)$ and Wnt1-cre $(+/-)::$ Pygo2 $(+/+)$. Significantly more hair follicles from Wnt1-cre(+/-)::Pygo(-/-) mice were at stage 3 at birth, whereas significantly more follicles were at stage 4 in Pygo2 newborn mice. Number animals analysed, three per genotype. Number hair staged, 302 (Pygo null) and 304 (Pygo). Bar, $50 \mu \mathrm{m}$ 
Fig. 3 Hair follicle formation is perturbed in Wnt1-cre $(+1$

-)::Pygo(-/-) mice. Left panel, morphology of mutant hair. Right panel, three of the four types of hair follicles, awl, auchen and zigzag hair were analysed in rare surviving Wnt1-cre::Pygo2(-/-) mice. There were too few guard hairs to collect meaningful data. In Wnt1-cre::Pygo2(-/-) the number of zig-zag hairs was significantly reduced by $\sim 39 \%$. As they should have the length of awl hair, zig-zag hairs were shorter by approximately one third compared to wild type zigzag hairs. There was a $73 \%$ significant increase in Awl hair, and a 2.5-fold increase in Auchen hair in Wnt1-cre(+/-)::Pygo(-/-) mice. At total of 490 hair from two Pygo null and 459 hair from two wild type animals were scored

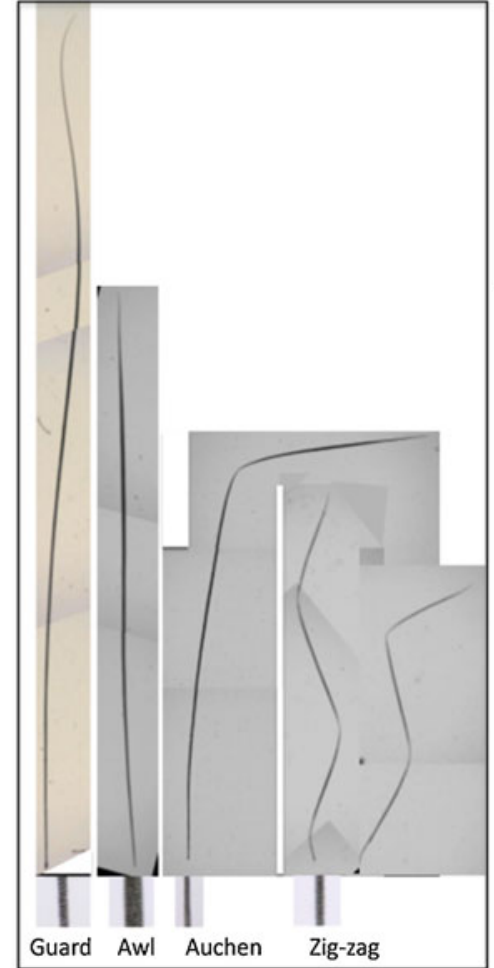

\begin{tabular}{|c|c|c|c|}
\hline \multicolumn{4}{|c|}{$\begin{array}{l}\text { Hair types } \\
\text { (Average number hair per visual field } \pm S D \text { ) }\end{array}$} \\
\hline & Pygo2 null & wt & p-value \\
\hline & $7.0 \pm 3$ & $11.4 \pm 6.3$ & 0.0 \\
\hline Awl & $13.0 \pm 11.8$ & $7.5 \pm 2.9$ & 0.03 \\
\hline Auchen & $2.5 \pm 1.7$ & $1.0 \pm 1.0$ & 0.0009 \\
\hline
\end{tabular}

In order to determine whether the number of neural crest cells present in hair follicles of mutant newborns was affected by the deletion of the Pygo2 gene, we analyzed Xgal stained sections of triple transgenic Wnt1-cre(+/-)::R26R(+/-)::Pygo2(-/-) mice and Wnt1-cre(+/-)::R26R(+/-)::Pygo2(+/+) control littermates. The portion of hair follicles that contained Xgal-positive cells was scored. There was a $10 \%$ decrease in hair follicle sections that contained neural crest cells in Wnt1-cre(+/-)::Pygo(-/-)
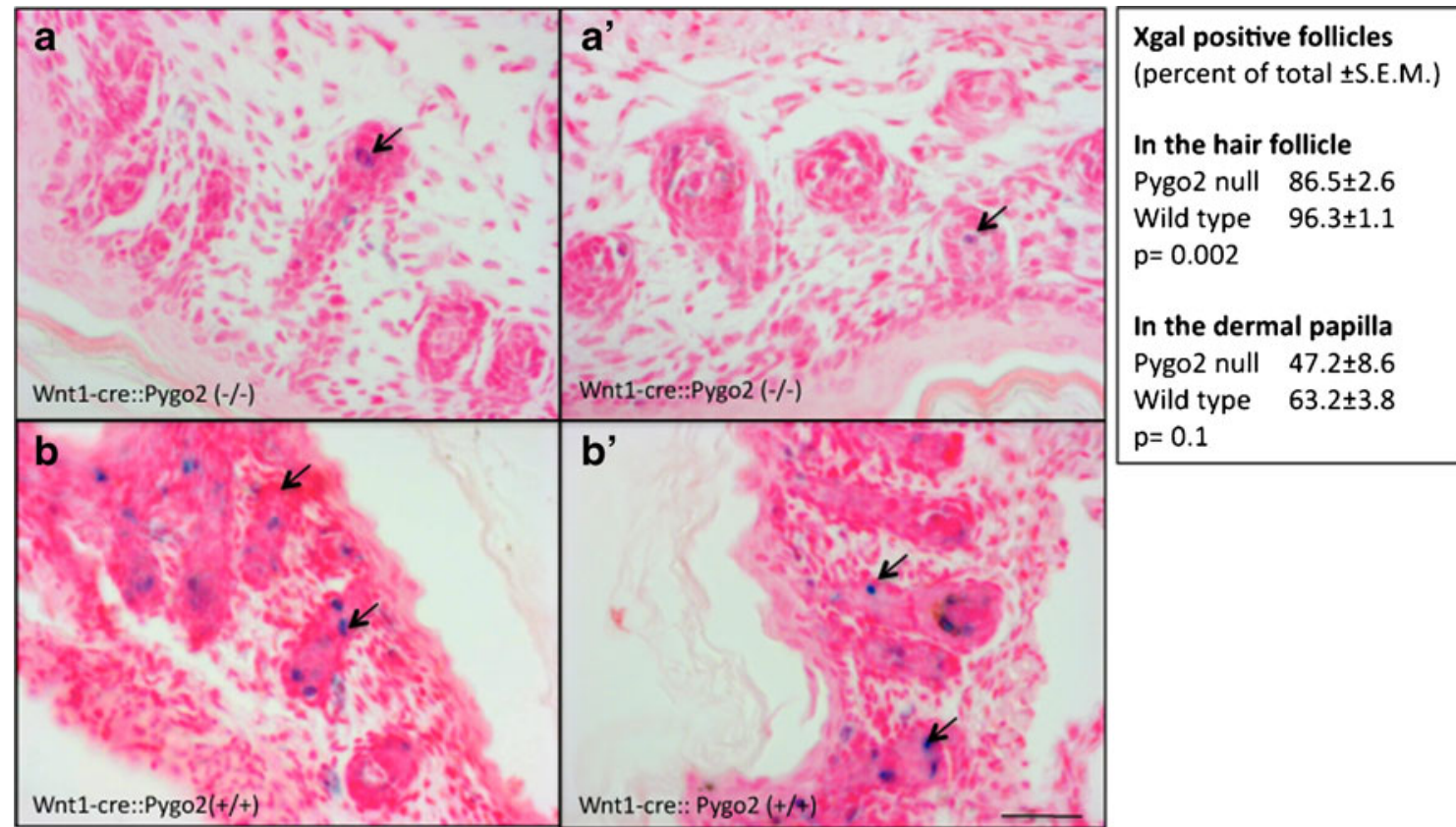

Fig. 4 Decrease of neural crest cells in hair follicles from Pygo null newborns. a, a' Two different fields of vision of hair follicles from back skin of Wnt1-cre::Pygo(-/-) newborn mice. $\mathbf{b}$, b' Hair follicles from
Wnt1-cre::Pygo(+/+) newborn mice. There was about a $\sim 10 \%$ significant decrease in hair follicle sections that contained detectable neural crest cells in the forming hair shaft. Bar, $50 \mu \mathrm{m}$ 


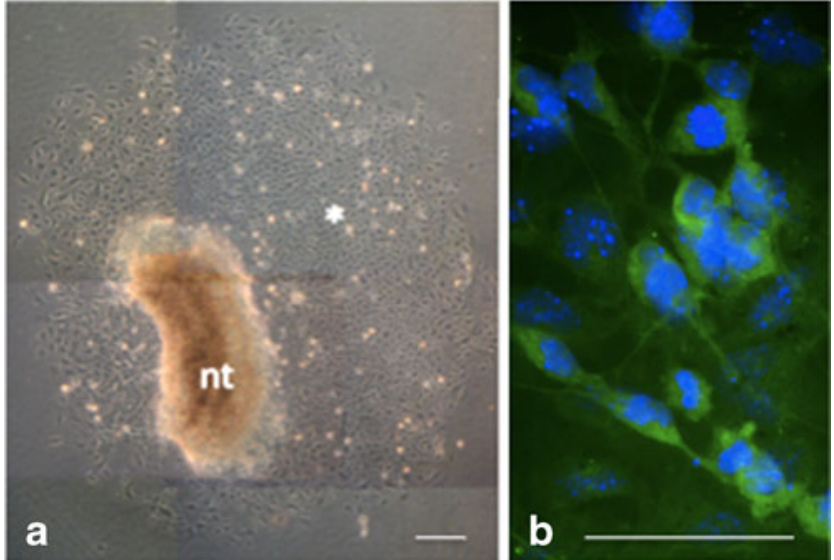

Fig. 5 Embryonic mouse neural crest cells express Eda-A1. a Neural tube explant from E9.5 C57Bl/6J mouse embryos. Eighteen hours postexplantation, neural tubes were surrounded by a halo of thousands of emigrating and proliferating neural crest cells. b Cultures were fixed at $18 \mathrm{~h}$ post-explantation and processed for immunocytochemistry with antibodies against Eda-A1. All neural crest cells showed Eda-A1 immunoreactivity; subsets of cells were intensely immunoreactive. Asterisk indicates neural crest cells; $n t$ neural tube. Number of explants stained and observed: 5 . Bars, $50 \mu \mathrm{m}$ mice compared to control littermates, indicating a decrease in the number of neural crest cells present in hair follicles of mutant neonates (Fig. 4).

Zig-zag hair development is dependent on Eda-A1/Edar signalling [38] and Eda-A1 is a Wnt target gene [7, 21]. As zig-zag hair numbers and morphology were affected by the mutation, we were interested in determining whether neural crest cells express Eda-A1. Neural tube explants from day 9.5 mouse embryos yielded large numbers of rapidly migrating and proliferating neural crest cells (Fig. 5a). Immunocytochemistry showed that neural crest cells were immunopositive for Eda-A1 (Fig. 5b). All cells were Eda-A1 immunoreactive, but there was a range of intensities of fluorescence. There were groups of cells showing intense immunofluorescence (Fig. 5b middle) intermingled with cells that showed low intensity of Eda-A1 fluorescence (e.g., Fig. 5b, upper left)

\section{Discussion}

Wnt signalling in the epidermis at the pre-placode stage, i.e. prior to hair stage 0 , is an absolute requirement for hair follicle

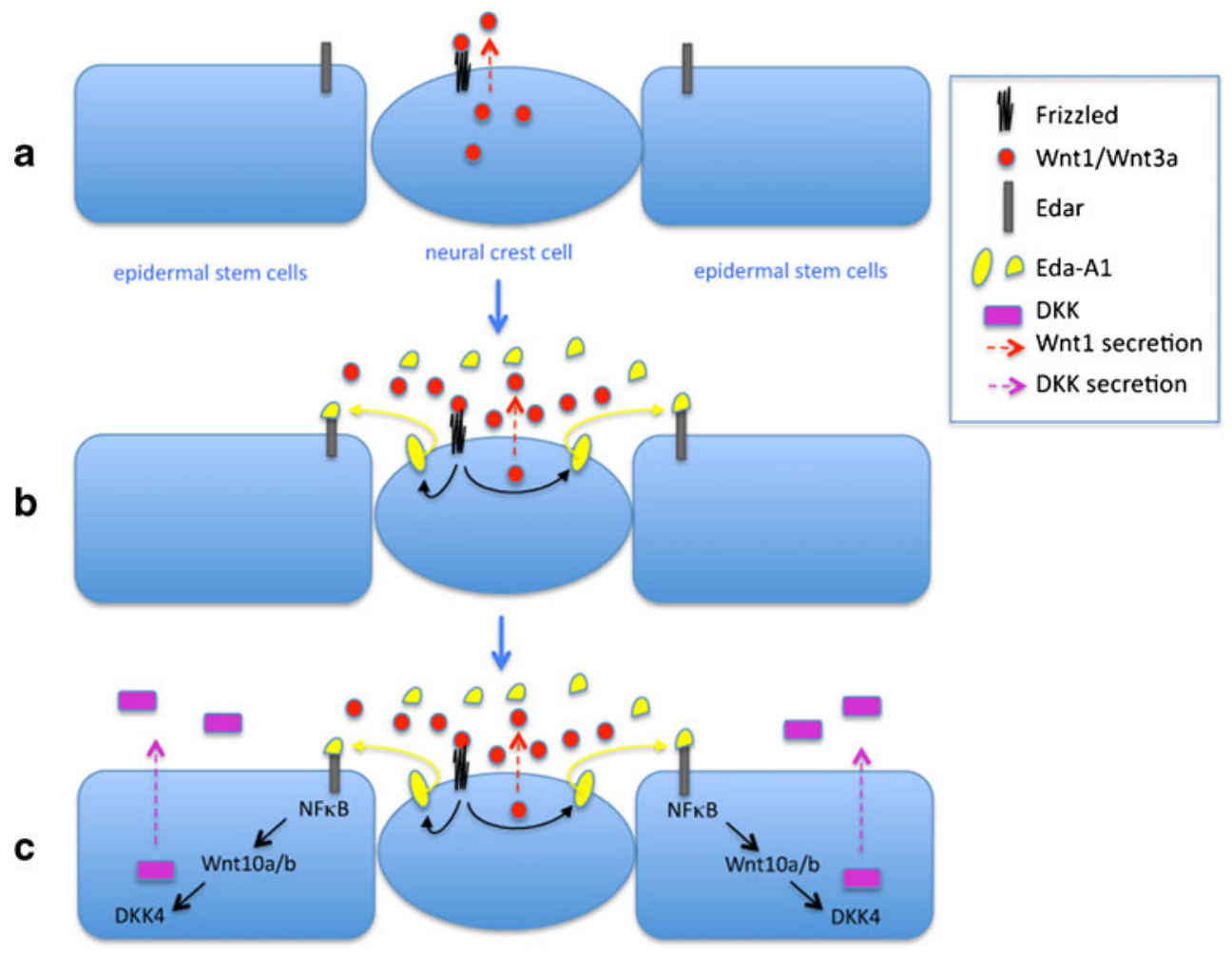

Fig. 6 Hypothetical model for mechanisms underlying pre-placode stage neural crest-derived epidermal Wnt signalling. a Neural crest cells that have invaded the ectoderm [34] are in close apposition with epidermal stem cells at pre-placode stages. Neural crest cells express Wnt proteins $[8,44]$ and their cognate receptors [43, 46, 47, 49]. Therefore neural crest cells can undergo autocrine Wnt signalling. Epidermal stem cells within the future placode express the Eda-A1 receptor, Edar [3, 32]. No activated beta-catenin indicative of Wnt signalling in the dermis is detected at that early stage of hair development [3]. b As a consequence of cell-autonomous Wnt signalling, neural crest cells produce Wnt target genes, including Eda-A1 ([21]; this study). c Eda-A1/Edar signalling in epidermal cells leads to DKK4 expression. In Wnt1-cre(+/-)::Pygo(-/-) mice, it is expected that the DKK:Wnt ratio is altered and Eda-A1 protein levels are reduced. Together these changes can explain the here observed disturbances in hair follicle thickness, hair density, as well as zig-zag hair formation and morphology 
induction $[10,15,28,38]$ - its origin is, however, unknown. Since canonical Wnt signalling is a characteristic of neural crest cells, because neural crest cells express Pygo2 [17] and invade the epidermis $[4,17,34,40]$, and since pre-placode epidermal areas express Pygo2 [22], we asked in this study whether neural crest cells could participate in regulating hair follicle formation. We found that deleting the Pygo2 gene specifically in neural crest cells during early embryonic development perturbed hair formation in diverse ways. Hair follicles were sparser and thinner in Wnt1-cre(+/-)::Pygo(-/-) newborns. There was a decrease in the number of zig-zag hair in surviving mutant animals and zig-zag hair morphology was altered. There was a delay in hair follicle development and a diminished number of neural crest cells present in hair follicles of Wnt1-cre(+/-)::Pygo(-/-) mice. Furthermore, we showed that mouse neural crest cells express Eda-A1. Li et al. [23] observed an approximate $30 \%$ decrease in hair density in global Pygo2 knockout animals. We observed a $19 \%$ decrease in hair density, which shows that the decrease in hair density in the absence of Pygo2 is to a large part neural crest-related.

Ectodermal $\mathrm{Wnt} / \beta$-catenin signalling as well as ectodermal Eda-1A signalling through its cognate receptor, Edar, and activation of the down-stream target genes, NFKB and $\mathrm{Wnt} 10 \mathrm{a} / \mathrm{b}$, are essential for zig-zag hair induction and morphology, respectively (Andl 2002) [1, 16, 24, 37, 38]. Eda-A1 is a Wnt target gene $[7,21]$ and is expressed in neural crest cells (this study), while the cognate receptor, Edar is induced by mesenchyme derived activin [21] but is expressed exclusively in the epidermis and becomes limited to the hair placodes $[1,9,16,25,48,50]$. The Eda-A1/Edar signalling network is thought to be involved in regulating hair thickness, as in humans enhanced Edar signalling leads to coarser hair [27]. Taken together, the reduction in hair thickness and perturbed zig-zag hair development in Wnt1-cre(+/ $-):: P y g o 2(-/-)$ mice can be explained by diminished EdaA1 production as a consequence of attenuated Wnt1 signalling in neural crest cells.

Other indications of perturbed hair formation was a delay in hair development in Wnt1-cre(+/-)::Pygo2(-/-) newborns and significantly fewer neural crest cells in hair follicles. Canonical Wnt signalling in neural crest cells is involved in neural crest initiation, migration, proliferation and differentiation $[12,14,29]$. Attenuated Wnt signalling as a consequence of deleting Pygo2 in neural crest cells can thus explain the reduced number of neural crest cells in hair follicles, which may compound the observed deficits in hair development. Neural crest cells are, however, known for their capacity to compensate for cell loss, as after partial ablation of the neural crest, neighbouring neural crest can change their pathways and fill in the gaps [20].

In addition to its role in canonical Wnt signalling, Pygo2 can also bind to the promoter of several histone genes in a cell context-specific way; in particular Pygo2 enhances acetylation of histone H3 [13, 26]. Whether altered histone modification plays a role in hair follicle induction remains to be determined.

Inductive fields where hair follicle induction takes place are proposed to be formed by interacting, self-organizing gradients of stimulatory and inhibitory signals (reaction-diffusion mechanism) that involve Wnt signalling and the Wnt inhibitor, DKK [35]. In view of the existing literature and our data in the present study we suggest a working model for the involvement of neural crest cells in hair follicle formation (Fig. 6). Neural crest cells express Wnt proteins, in particular Wnt1 [5] and Wnt3a [44], which activate the canonical Wnt pathway. Neural crest cells also express the cognate receptors frizzled (Fzd) and LRP [43, 46, 47, 49], enabling autocrine Wnt signalling in neural crest cells (Fig. 6a). As a result neural crest cells are able to produce the Wnt target gene Eda-A1 ([32]; this study). Eda-A1 is a membrane bound protein that gets cleaved and released as a soluble protein and could thus occupy Edar receptors on neighbouring epidermal cells (Fig. 6b). DKK4 is an Eda-A1/Edar target gene [9] and is transiently expressed in the epidermis in pre-placodal locations ([2]; Fig. 6c). DKK expression affects placode size and hair spacing $[2,9,35]$. Due to reduced Wnt signalling and consequent reduced Eda expression, placode size and hair spacing would thus be expected to be perturbed in Wnt1cre $(+/-)::$ Pygo(-/-) mice, which is in agreement with our observations. Additional work, which is beyond the scope of this study, will be required to corroborate the role of neural crest cells in hair development in the mouse.

Acknowledgments This work was supported by Medical Research Council grant 22358, and Newcastle University. MSB thanks Profs Steven Potter (Pygo2), Philippe Soriano (R26R-LacZ) and Andrew McMahon (Wnt1-cre) for providing the respective mouse lines, and Prof Heather Cordell for advice on statistical analysis.

Conflict of Interest The authors indicate no potential conflicts of interest.

Open Access This article is distributed under the terms of the Creative Commons Attribution License which permits any use, distribution, and reproduction in any medium, provided the original author(s) and the source are credited.

\section{References}

1. Andl, T., Reddy, S. T., Gaddapara, T., \& Millar, S. E. (2002). WNT signals are required for the initiation of hair follicle development. Developmental Cell, 2(5), 643-653.

2. Bazzi, H., Fantauzzo, K. A., Richardson, G. D., et al. (2007). The Wnt inhibitor, Dickkopf 4, is induced by canonical Wnt signalling during ectodermal appendage morphogenesis. Developmental Biology, 305(2), 498-507. Epub 2007 Mar 2.

3. Chen, D., Jarrell, A., Guo, C., et al. (2012). Dermal $\beta$-catenin activity in response to epidermal Wnt ligands is required for fibroblast proliferation and hair follicle initiation. Development, 139(8), 1522-1533. 
4. Clewes, O., Narytnyk, A., Gillinder, K. R., et al. (2011). Human epidermal neural crest stem cells (hEPI-NCSC)-characterization and directed differentiation into osteocytes and melanocytes. Stem Cell Reviews, 7(4), 799-814. doi:10.1007/s12015-011-9255-5.

5. Danielian, P. S., Muccino, D., Rowitch, D. H., et al. (1998). Modification of gene activity in mouse embryos in utero by a tamoxifen-inducible form of Cre recombinase. Current Biology, 8(24), 1323-1326.

6. Dunn, K. J., Brady, M., Ochsenbauer-Jambor, C., et al. (2005). WNT1 and WNT3a promote expansion of melanocytes through distinct modes of action. Pigment Cell Research, 18(3), 167-180.

7. Durmowicz, M. C., Cui, C. Y., \& Schlessinger, D. (2002). The EDA gene is a target of, but does not regulate Wnt signaling. Gene, 285(12), 203-211.

8. Echelard, Y., Vassileva, G., \& McMahon, A. P. (1994). Cis-acting regulatory sequences governing Wnt-1 expression in the developing mouse CNS. Development, 120(8), 2213-2224.

9. Fliniaux, I., Mikkola, M. L., Lefebvre, S., \& Thesleff, I. (2008). Identification of dkk4 as a target of Eda-A1/Edar pathway reveals an unexpected role of ectodysplasin as inhibitor of Wnt signalling in ectodermal placodes. Developmental Biology, 320(1), 60-71. doi:10. 1016/j.ydbio.2008.04.023. Epub 2008 Apr 26.

10. Fu, J., \& Hsu, W. (2012) Epidermal Wnt controls hair follicle induction by orchestrating dynamic signaling crosstalk between the epidermis and dermis. Journal of Investigative Dermatology. Nov 29. doi:10.1038/jid.2012.407. [Epub ahead of print].

11. Glotzer, D. J., Zelzer, E., \& Olsen, B. R. (2008). Impaired skin and hair follicle development in Runx2 deficient mice. Developmental Biology, 315(2), 459-473.

12. Grigoryan, T., Wend, P., Klaus, A., \& Birchmeier, W. (2008). Deciphering the function of canonical Wnt signals in development and disease: conditional loss- and gain-of-function mutations of betacatenin in mice. Genes \& Development, 22(17), 2308-2341. doi:10. 1101/gad.1686208.

13. Gu, B., Watanabe, K., \& Dai, X. (2012). Pygo2 regulates histone gene expression and H3 K56 acetylation in human mammary epithelial cells. Cell Cycle, 11(1), 79-87. doi:10.4161/cc.11.1.18402. Epub 2012 Jan 1.

14. Hari, L., Miescher, I., Shakhova, O., et al. (2012). Temporal control of neural crest lineage generation by $\mathrm{Wnt} / \beta$-catenin signaling. Development, 139(12), 2107-2117. doi:10.1242/dev.073064. Epub 2012 May 9.

15. Huelsken, J., Vogel, R., Erdmann, B., et al. (2001). beta-Catenin controls hair follicle morphogenesis and stem cell differentiation in the skin. Cell, 105(4), 533-545.

16. Headon, D. J., \& Overbeek, P. A. (1999). Involvement of a novel Tnf receptor homologue in hair follicle induction. Nature Genetics, 22(4), 370-374.

17. Hu, Y. F., Zhang, Z. J., \& Sieber-Blum, M. (2006). An epidermal neural crest stem cell (EPI-NCSC) molecular signature. Stem Cells, 24(12), 2692-2702. Epub 2006 Aug 24.

18. Ito, K., Morita, T., \& Sieber-Blum, M. (1993). In vitro clonal analysis of mouse neural crest development. Developmental Biology, 157(2), $517-525$.

19. Jessen, S., Gu, B., \& Dai, X. (2008). Pygopus and the Wnt signaling pathway: a diverse set of connections. Bioessays, 30(5), 448-456. doi:10.1002/bies.20757.

20. Kulesa, P., Bronner-Fraser, M., \& Fraser, S. (2000). In ovo time-lapse analysis after dorsal neural tube ablation shows rerouting of chick hindbrain neural crest. Development, 127, 2843-2852.

21. Laurikkala, J., Pispa, J., Jung, H. S., et al. (2002). Regulation of hair follicle development by the TNF signal ectodysplasin and its receptor Edar. Development, 129(10), 2541-2553.

22. Li, B., Mackay, D. R., Ma, J., \& Dai, X. (2004). Cloning and developmental expression of mouse pygopus 2, a putative Wnt signaling component. Genomics, 84(2), 398-405.
23. Li, B., Rhéaume, C., Teng, A., et al. (2007). Developmental phenotypes and reduced Wnt signaling in mice deficient for pygopus 2. Genesis, 45(5), 318-325.

24. Mikkola, M. L., Pispa, J., Pekkanen, M., et al. (1999). Ectodysplasin, a protein required for epithelial morphogenesis, is a novel TNF homologue and promotes cell-matrix adhesion. Mechanisms of Development, 88(2), 133-146.

25. Mikkola, M. L., \& Thesleff, I. (2003). Ectodysplasin signaling in development. Cytokine \& Growth Factor Reviews, 14(3-4), 211-224.

26. Miller, T. C., Rutherford, T. J., Johnson, C. M., et al. (2010). Allosteric remodelling of the histone $\mathrm{H} 3$ binding pocket in the Pygo2 PHD finger triggered by its binding to the B9L/BCL9 co-factor. Journal of Molecular Biology, 401(5), 969-984. doi:10.1016/j.jmb. 2010.07.007. Epub 2010 Jul 14

27. Mou, C., Thomason, H. A., Willan, P. M., et al. (2008). Enhanced ectodysplasin-A receptor (EDAR) signaling alters multiple fiber characteristics to produce the East Asian hair form. Human Mutation, 29(12), 1405-1411. doi:10.1002/humu.20795.

28. Närhi, K., Järvinen, E., Birchmeier, W., et al. (2008). Sustained epithelial beta-catenin activity induces precocious hair development but disrupts hair follicle down-growth and hair shaft formation. Development, 135(6), 1019-1028. doi:10.1242/dev.016550.

29. Patapoutian, A., \& Reichardt, L. F. (2000). Roles of Wnt proteins in neural development and maintenance. Current Opinion in Neurobiology, 10(3), 392-399.

30. Pennisi, D. J., Wilkinson, L., Kolle, G., et al. (2007). Crim1KST264/ KST264 mice display a disruption of the Crim1 gene resulting in perinatal lethality with defects in multiple organ systems. Developmental Dynamics, 236(2), 502-511.

31. Paus, R., Müller-Röver, S., Van Der Veen, C., et al. (1999). A comprehensive guide for the recognition and classification of distinct stages of hair follicle morphogenesis. Journal of Investigative Dermatology, 113(4), 523-532.

32. Pummila, M., Fliniaux, I., Jaatinen, R., et al. (2007). Ectodysplasin has a dual role in ectodermal organogenesis: inhibition of Bmp activity and induction of Shh expression. Development, 134(1), 117-125.

33. Rendl, M., Lewis, L., \& Fuchs, E. (2005). Molecular dissection of mesenchymal-epithelial interactions in the hair follicle. PLoS Biol, 3(11), e331. Epub 2005 Sep 20.

34. Richardson, M. K., \& Sieber-Blum, M. (1993). Pluripotent neural crest cells in the developing skin of the quail embryo. Developmental Biology, 157(2), 348-358.

35. Sick, S., Reinker, S., Timmer, J., \& Schlake, T. (2006). WNT and DKK determine hair follicle spacing through a reaction-diffusion mechanism. Science, 314(5804), 1447-1450. Epub 2006 Nov 2.

36. Schlake, T. (2007). Determination of hair structure and shape. Seminars in Cell \& Developmental Biology, 18, 267-273.

37. Schmidt-Ullrich, R., Aebischer, T., Hülsken, J., et al. (2001). Requirement of NF-kappaB/Rel for the development of hair follicles and other epidermal appendices. Development, 128(19), 3843-3853.

38. Schmidt-Ullrich, R., \& Paus, R. (2005). Molecular principles of hair follicle induction and morphogenesis. Bioessays, 27(3), 247-261.

39. Schwab, K. R., Patterson, L. T., Hartman, H. A., et al. (2007). Pygo1 and Pygo 2 roles in Wnt signaling in mammalian kidney development. BMC Biology, 5, 15.

40. Sieber-Blum, M., Grim, M., Hu, Y. F., \& Szeder, V. (2004). Pluripotent neural crest stem cells in the adult hair follicle. Developmental Dynamics, 231(2), 258-269.

41. Sieber-Blum, M., \& Hu, Y. (2008). Epidermal neural crest stem cells (EPI-NCSC) and pluripotency. Stem Cell Reviews, 4(4), 256-260. doi:10.1007/s12015-008-9042-0. Review.

42. Soriano, P. (1999). Generalized lacZ expression with the ROSA26 Cre reporter strain. Nature Genetics, 21(1), 70-71.

43. Sisson, B. E., \& Topczewski, J. (2009). Expression of five frizzleds during zebrafish craniofacial development. Gene Expression 
Patterns, 9(7), 520-527. doi:10.1016/j.gep.2009.07.003. Epub 2009 Jul 10.

44. Sun, X., Zhang, R., Lin, X., \& Xu, X. (2008). Wnt3a regulates the development of cardiac neural crest cells by modulating expression of cysteine-rich intestinal protein 2 in rhombomere 6. Circulation Research, 102(7), 831-839. doi:10.1161/CIRCRESAHA.107.166488. Epub 2008 Feb 21.

45. Szeder, V., Grim, M., Halata, Z., \& Sieber-Blum, M. (2003). Neural crest origin of mammalian Merkel cells. Developmental Biology, 253(2), 258263.

46. van Gijn, M. E., Blankesteijn, W. M., Smits, J. F., et al. (2001). Frizzled 2 is transiently expressed in neural crest-containing areas during development of the heart and great arteries in the mouse. Anat Embryol (Berl)., 203(3), 185-192.
47. Wu, J., Saint-Jeannet, J. P., \& Klein, P. S. (2003). Wnt-frizzled signaling in neural crest formation. Trends in Neurosciences, 26(1), 40-45.

48. Zhang, Y., Tomann, P., Andl, T., et al. (2009). Reciprocal requirements for EDA/EDAR/NF-kappaB and Wnt/beta-catenin signaling pathways in hair follicle induction. Developmental Cell, 17(1), 4961. doi:10.1016/j.devcel.2009.05.011.

49. Zhou, Y., \& Snead, M. L. (2008). Derivation of cranial neural crestlike cells from human embryonic stem cells. Biochemical and Biophysical Research Communications, 376(3), 542-547. doi:10.1016/j. bbrc.2008.09.032. Epub 2008 Sep 18.

50. Zhou, P., Byrne, C., Jacobs, J., \& Fuchs, E. (1995). Lymphoid enhancer factor 1 directs hair follicle patterning and epithelial cell fate. Genes \& Development, 9(6), 700-713. 